\title{
A Novel environmental nano-catalyst of zeolite amended with carbon nanotube/silver nanoparticles decorated carbon paste electrode for electro-oxidation of propylene glycol
}

Soha Abdel-Gawad (D Soha.gawad@yahoo.com )

Cairo University

Amany Fekry

Cairo University

\section{Research Article}

Keywords: Electrocatalysis, carbon paste electrode, propylene glycol oxidation, electrochemical impedance spectroscopy, cyclic voltammetry

Posted Date: February 28th, 2022

DOI: https://doi.org/10.21203/rs.3.rs-1296937/v1

License: (c) (1) This work is licensed under a Creative Commons Attribution 4.0 International License. Read Full License 


\section{Abstract}

A novel environmental nano-catalyst based on zeolite (ZE) adjusted with carbon nanotube (CNT)/silver nanoparticles (AgNPS) ornamented carbon paste electrode (CPE) is used for electrochemical oxidation of propylene glycol (PG) in $0.5 \mathrm{M} \mathrm{H}_{2} \mathrm{SO}_{4}$ solution. The techniques like cyclic voltammetry (CV), chronoamperometry (CA) and electrochemical impedance spectroscopy (EIS) are utilized to achieve the catalytic performance. Surface characteristics are achieved by means of Scanning electron microscopic (SEM) and Energy dispersive X-ray analysis (EDX) techniques. Enhancing the loading magnitude of CNT into catalyst's ingredient can meaningfully develop the catalytic activity of the electrocatalyst towards propylene oxidation. The impact of altering the concentration of propylene glycol and the scanning rate on the resulting electrocatalyst performance during the oxidation cycle is considered.

Chronoamperograms present an amplify of the steady state oxidation current density values after addition of these nano-catalysts. A promising catalytic stability of nano-catalyst has been achieved in electing its use for propylene glycol electro-oxidation in fuel cells applications.

\section{Introduction}

The world has faced energy shock because fossil fuel reserves are rapidly exhausted. Also, the utilization of fossil fuels is being perceived for its harmful influences that may cause a natural and social crisis [1, 2]. Thus, it is important to look for a practical alternate fuel and make new energy conversion instruments to resolve these energy cohort difficulties [3, 4]. Direct alcohol fuel cells dependent on small organic molecules have great consideration as probable power devices, mainly for portable electronic devices and electric vehicles in view of their high energy density, efficiency, low ecological contamination and low working temperature $[5,6]$. The electrocatalytic oxidations of different small organic molecules on various edited electrodes have been examined for application in fuel cells [7-13]. Most of recent reports, polyalcohol such as ethylene glycol, propylene glycol and glycerol is a good choice in fuel cells due to its high reactivity in electro-oxidation, inflammability, lower toxicity and high boiling point that allows tranquil handling and storage $[14,15]$. Polyalcohol fuels are valuable due to they can be produced from renewable sources $[16,17]$. Furthermore, to improve the efficacy of fuel employment, active catalysts, having enough ability to break strong $\mathrm{C}-\mathrm{C}$ bond in polyalcohol are highly wanted [18-20] .The electrochemical oxidation of polyalcohol on noble metals such as platinum, palladium, and gold has been demonstrated in several recent investigations. Sadiki et al. [21] Studied the polyalcohol oxidation in alkaline media by improve the efficacy of the palladium catalysts edited by several adatoms (antimony, tin, lead). The existence of bimetallic surface leads to enhance the oxidation rate of these alcohols. Munoz et al. [22] presented that a carbon-supported Pd-Cu nanocatalyst can increase the polyalcohol oxidation rate in alkaline medium. The developments have been accredited to both electronic and bifunctional effects. Furthermore; the $\mathrm{Cu} / \mathrm{Pd}$ ratio seems to have a noteworthy impression on the rate of oxidation $[23,24]$. To make the electro-oxidation of polyalcohol practically valuable, novel inexpensive and selective catalysts are required. Catalyst plays a crucial role in electrochemical energy conversion in fuel cell. Carbon paste electrode (CPE) is the most popular catalytic support material due to their strong 
electronic conductivity, comparative stability in different media and high effective surface area [2527].The nano-modified electrodes are substantial to improve the catalytic activity in order to reduce production costs.

Recently, Silver nano particles (AgNPs) have potentially demonstrated in electrocatalysis applications. AgNPs can act as a conduction center to improve the transmission of electrons and deliver exceptional catalytic activity $[28,29]$. Carbon nanotubes (CNTS) are porous constituents with special characteristics, high efficiency of surface area, strong conductivity, and chemical stability [30]. Carbon nanotube has high electrocatalytic activity in numerous substances and therefore suitable for building various electrocatalyst with high efficiency [31-34]. Zeolites are known as microporous crystalline aluminosilicate materials with high surface area, adsorptive and molecular sieving materials. Zeolites are unique materials, which can be exploited in the development of modified electrodes with high chemical and thermal stability [35-38]. Nevertheless, the propylene glycol oxidation in acidic media is quiet not fully revealed and requires to be additional studied. It is well recognized that carbon paste electrode with nano-material showed electrocatalytic act toward propylene glycol oxidation in acidic medium due to strong adsorbability of PG molecules on the nano-material surface.

The aim of this work to produce a novel environmental nano-catalyst created from modified carbon paste electrode with zeolite, carbon nanotube and silver nanoparticles. The catalyst with large surface area, simple and low cost construction is recommended for propylene glycol oxidation in acidic medium.

\section{Experimental}

\subsection{Materials and reagents}

The Chemicals are graphite, multi walled carbon nanotube, zeolite and silver nanoparticles powder (dispersion nanoparticles, < $100 \mathrm{~nm}$ ), propylene glycol (99, 8\%), Sigma-Aldrich (USA) and were used without further purifications. All solutions are prepared utilizing triple distilled water. All experiments were achieved at ambient temperature.

\subsection{SMWZCPE modified electrode preparation}

In order to develop the catalytic activity of modified electrode different weights of zeolite and silver nanoparticles were investigated. Also the loading of carbon nanotube into the catalyst $(0.01-0.04 \mathrm{mg})$ was considered. The best modification for carbon paste (CPE) electrode was made by mixing $5 \mathrm{~g}$ graphite powder with drops of paraffin oil on a glassy mortar, then $0.04 \mathrm{mg}$ of carbon nanotube, $5 \mathrm{mg}$ of silver nanoparticles and $0.1 \mathrm{~g}$ zeolite were added to set up the catalyst (SMWZCPE), which was utilized in all experiments. The carbon paste was packed in a Teflon tube with pressing to acquire a smooth surface.

\subsection{Cell and Apparatus}

A three-electrode cell enclosing a platinum rode as a counter electrode (CE), saturated calomel electrode (SCE) as a reference electrode (RE) and (SMWZCPE) as the working electrode (WE) was used. Cyclic 
voltammetry (CV), chronoamperometry (CA) and Electrochemical impedance spectroscopic (EIS) measurements are achieved by EC-Lab SP 150 Potentiostat electrochemical workstation. EIS are done at $10 \mathrm{mV}$ ac amplitude at frequency of $1.0 \mathrm{mHz}$ to $100 \mathrm{kHz}$. EC-Lab software is operated for demonstrating. Scanning electron microscopic (SEM) measurements were performed by SEM Model Quanta 250 FEG (Field Emission Gun) related with EDX Unit (Energy Dispersive X-ray Analyses) (FEl company, Netherlands).

\section{Results And Discussion}

\subsection{Characterization of the modified electrocatalyst}

Figure 1A shows the SEM images of the SMWZCPE modified electrode which reveals that silver nanoparticles, CNT and zeolite dispersed in a uniform distribution on the graphite paste.

Figure 1B demonstrates well the EDX spectrum of SMWZCPE which approves the existence of $\mathrm{C}, \mathrm{O}, \mathrm{Ag}, \mathrm{Al}$ and $\mathrm{Si}$ by a good percentage in the formed electrocatalyst. The uniform spreading of the elements along the entire catalyst surface offered an opportunity to improve the active electrochemical surface area and increasing the elecrocatalytic efficiency.

\subsection{Electrocatalytic oxidation of propylene glycol}

Figure 2 presents the CVs obtained at the bare carbon paste electrode in $0.5 \mathrm{M} \mathrm{H}_{2} \mathrm{SO}_{4}$ and modified electrode SMWZCPE in $0.5 \mathrm{M} \mathrm{H}_{2} \mathrm{SO}_{4}$ with and without $0.5 \mathrm{M}$ propylene glycol at a scan rate of $100 \mathrm{mVs}^{-}$ 1. CV verified at the bare electrode seemed unremarkable indicated catalytic inactivity. However, the CVs of the modified electrode offered a developed electro-catalytic activity towards propylene oxidation. The oxidation of propylene at modified electrode reveals a reversible oxidation peak at $0.7 \mathrm{~V}$ and $0.38 \mathrm{~V}$ with a peak current $\sim 50$ times more than the bare one. This indicated that the electro catalytic activity of the modified electrode surface can be improved upon addition of zeolite, silver nanoparticles to the carbon nanotube matrix where a large effective surface area was obtained inducing higher adsorptivity of propylene through active hydroxyl function group to the modified electrode surface.

Electrochemical impedance spectroscopy technique is applied to examine the conductivity (catalytic activity) of the modified electrode towards propylene oxidation which is inversely proportional to the impedance. EIS scans distinguished at the peak potential $0.7 \mathrm{~V}$ for bare in $0.5 \mathrm{M} \mathrm{H}_{2} \mathrm{SO}_{4}$ and SMWZCPE electrode in $0.5 \mathrm{M} \mathrm{H}_{2} \mathrm{SO}_{4}$ with and without $0.5 \mathrm{M}$ propylene glycol. Figure 3 as Nyquist plots showed a semi-circle links to a charge transfer resistance and a line links to a diffusion process at both high and low frequencies, respectively. The experimental results were fitted with one-time constant model (Fig. 3 inset) including $R_{S}$ (solution resistance), $R_{1}$ (charge transfer resistance), $W$ (Warburg impedance linked to diffuesion prcess) and $Q_{1}$ (constant phase element of capacitance). Constant phase element was attributed to microscopic roughness and surface heterogeneity $[39,40]$. Bare electrode show a large semicircle diameter than that of modified SMWZCPE electrode signifing that impedance reduced and 
conductivity upsurges. These results support well the high oxidation peak current acquired from CVs response for modified SMWZCPE electrode.

The impedance $\left(\mathrm{Z}_{\mathrm{CPE}}\right)$ of a constant phase element is:

$\mathrm{Z}_{\mathrm{CPE}}=\left[\mathrm{C}(\mathrm{j} \omega)^{\mathrm{a}}\right]^{-1}$

Where $a$ is an exponent account for surface heterogeneity, $0 \leq a \leq 1, j$ is the imaginary number $(j=$ $\left.(-1)^{1 / 2}\right), \omega=2 \pi f$ is the angular frequency in $\mathrm{rad} / \mathrm{s}, \mathrm{f}$ is the frequency in $\mathrm{Hz}=\mathrm{S}^{-1}$ [41-43]. The EIS outcomes have confirmed the conclusions drawn from the above cyclic voltammetry experiments. The outcomes of EIS analysis are listed in Table 1.

Table 1

Electrochemical impedance parameters.

\begin{tabular}{|lccccc|}
\hline sample & $\mathbf{R}_{1} / \mathbf{k} \boldsymbol{\Omega}$ & $\mathbf{Q}_{1} / \mu \mathrm{F}$ & $\mathbf{a}$ & $\mathrm{W} / \mathrm{k} \Omega \mathrm{cm}^{2} \mathbf{s}^{-1 / 2}$ & $\mathrm{Rs} / \boldsymbol{\Omega}$ \\
\hline Bare & 19.2 & 11.1 & 0.78 & 9.8 & 21 \\
\hline SMWZCPE/0.5 $\mathrm{M} \mathrm{H}_{2} \mathrm{SO}_{4}$ & 10.5 & 14.3 & 0.81 & 7.3 & 37 \\
\hline SMWZCPE/0.5 M prop + 0.5 $\mathrm{M} \mathrm{H}_{2} \mathrm{SO}_{4}$ & 7.60 & 17.1 & 0.84 & 2.1 & 35 \\
\hline
\end{tabular}

The outecomes certified well CV data, where SMWZCPE electrode have the highest current and lowest impedance values.

\subsection{Impact of carbon nanotube loading}

The loading of CNT into the catalyst ingredients has a substantial influence on the catalytic activity of the modified electerode towards propylene oxidation due to growth of surface area. Figure 4 displays the CVs respone for propylene oxidation on modified electrode SMWZCPE with various loading of CNT (0.01-0.04 mg) in $0.5 \mathrm{M} \mathrm{H}_{2} \mathrm{SO}_{4}$ at scan rate of $100 \mathrm{mVs}^{-1}$. The propylene oxidation is reliant on the loading amount of CNT and anodic peak current increase with the increase in CNT loading in the synthesized electrocatalyst (direct relationship). Also, the onset potential shifts to more negative values for the best performing. As clearly interpreted, the increase in anodic peak currents indicates a corresponding increase in avaliable active sites with higher adsorption extent for hydroxyl group, which required for propylene oxidation [31-33].

\subsection{Effect of scan rate}

Effect of varying the potential scan rate ( $v$ ranging from 10 to $400 \mathrm{mVs}^{-1}$ ) was performed on modified SMWZCPE electrode in $0.5 \mathrm{M} \mathrm{H}_{2} \mathrm{SO}_{4}$ in absence of propylene glycol to confirm the electrochemical activity of the catalyst in aqueous solution (Fig. 5). Increasing the scan rate resulted in higher anodic peak current density and positive shift occurs in the forward peak potential. A linear relationship between the anodic peak current and square root of the scan rate was gotten as shown in the inset of the figure, with the following equation: $I_{p}(\mu A)=34.13+3.71 v^{1 / 2}\left(\mathrm{mVs}^{-1}\right)\left(r^{2}=0.9766\right)$. 
The impact of the potential scan rate ( $\mathrm{v}$ ranging from 10 to $\left.500 \mathrm{mVs}^{-1}\right)$ on the electrocatalytic anodic peak current of modified electrode SMWZCPE was also achieved in $0.5 \mathrm{M} \mathrm{H}_{2} \mathrm{SO}_{4}$ with $0.5 \mathrm{M}$ propylene glycol and established in (Fig. 6). As the scan rate increase (10-500 mV/s), the oxidation peak current amplified constantly and the peak potential moved positively. The plot of anodic peak current and square root of the scan rate (Inset $B$ ) leads to a linear relation: $I_{p}(\mu A)=91.22+2.77 v^{1 / 2}\left(\mathrm{mVs}^{-1}\right)\left(r^{2}=0.9466\right)$, which approves that the oxidation process of propylene glycol is diffusion controlled mechanism with some adsorption $[44,45]$.

\subsection{Effect of propylene glycol concentration}

The synthesized electrode was applied to distinguish the impact of propylene concentration for fuel cells application. The oxidation of propylene in the range 0.01 to $0.5 \mathrm{~mol} / \mathrm{I}$ was considered on this electrode. Figure 7 shows the conduct of this modified electrode for various propylene concentration from 0.01 to $0.5 \mathrm{~mol} / \mathrm{L}$ by $\mathrm{CVs}$ at the scan rate of $50 \mathrm{mV} \mathrm{s}^{-1}$. The propylene oxidation curves expose that anodic current peaks increase with expanding propylene concentration [46, 47]. This obtained results confirm that our modified electrode SMWZCPE act as effective catalyst for the oxidation of propylene in $0.5 \mathrm{M}$ $\mathrm{H}_{2} \mathrm{SO}_{4}$. Figure 7 (inset $B$ ) demonstrates a linearity by: $\mathrm{I}_{\mathrm{p}}(\mu \mathrm{A})=23.27+218 \mathrm{C}\left(\mathrm{r}^{2}=0.9956\right)$. It's suggested that the above relationship between Ip and [propylene] is owing to a diffusion-controlled mechanism.

\subsection{Stability of an electrocatalyst}

The stability of an electrocatalyst is an essential and evaluated by chronoamperomety. The chronoamperometric curves were obtained in the solution of $0.5 \mathrm{~mol} / \mathrm{I} \mathrm{H}_{2} \mathrm{SO}_{4}$ containing $(0.01-0.5 \mathrm{~mol} / \mathrm{l}$ ) propylene for 20 minutes at constant potential $0.7 \mathrm{~V}$. Figure 8 demonstrate current - time relation for different concentrations of propylene glycol, in the first the modified electrode SMWZCPE reveals continous decay of anodic oxidation current and after $\sim 2.5$ min reached relatively stable value until the end of experiment ( 20 mins). This denotes good mechanical and electrocatalytic constancy of the modified electrode toward PG oxidation.

Finally, based on the obtained outcomes its confirm that SMWZCPE modified electrode shows good promises to improve the activity of oxidation reaction of propylene glycol in acidic medium fuel cells.

\section{Conclusion}

1. A novel environmental nano-catalyst successfully prepared constructed by modified carbon paste electrode with zeolite, carbon nanotube and silver nanoparticles .

2. The characterization of the electrode SEM and EDX analysis shows that a well dispersed zeolite, CNT with the existence of silver nanoparticles occurs with a good percentage on the surface.

3. Electrochemical measurements discovered the exceptional electrocatalytic activity of nano-catalyst for oxidizing propylene.

4. Propylene oxidation progression was following diffusion - controlled process at electrocatalyst surface. 
5. Enhancing CNT content developed the attained anodic peak current until greatest performance at the electrocatalyst comprising $0.04 \mathrm{mg}$ CNT.

6. The proposed SMWZCPE modified electrode shows acceptable stability towards propylene glycol oxidation.

\section{Declarations}

\section{Data availability}

'Not applicable'

\section{References}

1. Q. Lin, Y. Wei, W. Liu, Y. Yu, J. Hu, Electrocatalytic oxidation of ethylene glycol and glycerol on nickel ion implanted-modified indium tin oxide electrode, international journal of hydrogen energy, 42 (2017) 1403-1411.

2. N.R. Stradiotto, K.E. Toghill, L. Xiao, A. Moshar, R.G. Compton, The fabrication and characterization of a nickel nanoparticle modified boron doped diamond electrode for electrocatalysis of primary alcohol oxidation, Electroanalysis: An International Journal Devoted to Fundamental and Practical Aspects of Electroanalysis, 21 (2009) 2627-2633.

3. F. Wang, D. Ouyang, Z. Zhou, S.J. Page, D. Liu, X. Zhao, Lignocellulosic biomass as sustainable feedstock and materials for power generation and energy storage, Journal of Energy Chemistry, 57 (2021) 247-280.

4. B. Boekaerts, B.F. Sels, Catalytic advancements in carboxylic acid ketonization and its perspectives on biomass valorisation, Applied Catalysis B: Environmental, 283 (2021) 119607.

5. X. Tarrús, M. Montiel, E. Vallés, E. Gómez, Electrocatalytic oxidation of methanol on CoNi electrodeposited materials, International Journal of hydrogen energy, 39 (2014) 6705-6713.

6. H.J. Jung, S.J. Lee, R. Koutavarapu, S.K. Kim, H.C. Choi, M.Y. Choi, Enhanced catalytic dechlorination of 1, 2-dichlorobenzene using $\mathrm{Ni} / \mathrm{Pd}$ bimetallic nanoparticles prepared by a pulsed laser ablation in liquid, Catalysts, 8 (2018) 390.

7. Y. Yu, T. Wang, Y. Fu, W. Su, J. Hu, Platinum nanoparticles ion-implanted-modified indium tin oxide electrode for electrocatalytic oxidation of formaldehyde, International journal of hydrogen energy, 39 (2014) 17617-17621.

8. Y. Yu, M. Jia, H. Tian, J. Hu, The fabrication of silver ion implantation-modified electrode and its application in electrocatalytic oxidation of formaldehyde, Journal of Power Sources, 267 (2014) 123-127.

9. J. Joo, T. Uchida, A. Cuesta, M.T. Koper, M. Osawa, Importance of acid-base equilibrium in electrocatalytic oxidation of formic acid on platinum, Journal of the American Chemical Society, 135 (2013) 9991-9994. 
10. C. Lamy, E. Belgsir, J. Leger, Electrocatalytic oxidation of aliphatic alcohols: Application to the direct alcohol fuel cell (DAFC), Journal of Applied Electrochemistry, 31 (2001) 799-809.

11. J. Macak, P. Barczuk, H. Tsuchiya, M. Nowakowska, A. Ghicov, M. Chojak, S. Bauer, S. Virtanen, P. Kulesza, P. Schmuki, Self-organized nanotubular TiO2 matrix as support for dispersed Pt/Ru nanoparticles: Enhancement of the electrocatalytic oxidation of methanol, Electrochemistry Communications, 7 (2005) 1417-1422.

12. G.-Y. Gao, D.-J. Guo, H.-L. Li, Electrocatalytic oxidation of formaldehyde on palladium nanoparticles supported on multi-walled carbon nanotubes, Journal of Power Sources, 162 (2006) 1094-1098.

13. H. Cao, Z. Fan, G. Hou, Y. Tang, G. Zheng, Ball-flower-shaped Ni nanoparticles on Cu modified TiO2 nanotube arrays for electrocatalytic oxidation of methanol, Electrochimica Acta, 125 (2014) 275281.

14. T. Ramulifho, K.I. Ozoemena, R.M. Modibedi, C.J. Jafta, M.K. Mathe, Electrocatalytic oxidation of ethylene glycol at palladium-bimetallic nanocatalysts ( $\mathrm{PdSn}$ and $\mathrm{PdNi}$ ) supported on sulfonatefunctionalised multi-walled carbon nanotubes, Journal of Electroanalytical Chemistry, 692 (2013) 26-30.

15. W. Xiong, X.-K. Gu, Z. Zhang, P. Chai, Y. Zang, Z. Yu, D. Li, H. Zhang, Z. Liu, W. Huang, Fine cubic Cu2O nanocrystals as highly selective catalyst for propylene epoxidation with molecular oxygen, Nature communications, 12 (2021) 1-8.

16. P.S. Fernández, M.E. Martins, G.A. Camara, New insights about the electro-oxidation of glycerol on platinum nanoparticles supported on multi-walled carbon nanotubes, Electrochimica Acta, 66 (2012) 180-187.

17. S.J. Khatib, S. Oyama, Direct oxidation of propylene to propylene oxide with molecular oxygen: A review, Catalysis Reviews, 57 (2015) 306-344.

18. J.F. Gomes, F.B.C. De Paula, L.H.S. Gasparotto, G. Tremiliosi-Filho, The influence of the Pt crystalline surface orientation on the glycerol electro-oxidation in acidic media, Electrochimica Acta, 76 (2012) 88-93.

19. S. Shelley, A renewable route to propylene glycol, Chem. Eng. Prog, 103 (2007) 6-9.

20. D.Z. Jeffery, G.A. Camara, The formation of carbon dioxide during glycerol electrooxidation in alkaline media: first spectroscopic evidences, Electrochemistry Communications, 12 (2010) 11291132.

21. A. Sadiki, P. Vo, S. Hu, T.S. Copenhaver, L. Scudiero, S. Ha, J.L. Haan, Increased electrochemical oxidation rate of alcohols in alkaline media on palladium surfaces electrochemically modified by antimony, lead, and tin, Electrochimica Acta, 139 (2014) 302-307.

22. F. Munoz, C. Hua, T. Kwong, L. Tran, T.Q. Nguyen, J.L. Haan, Palladium-copper electrocatalyst for the promotion of the electrochemical oxidation of polyalcohol fuels in the alkaline direct alcohol fuel cell, Applied Catalysis B: Environmental, 174 (2015) 323-328.

23. O. Muneeb, J. Estrada, L. Tran, K. Nguyen, J. Flores, S. Hu, A.M. Fry-Petit, L. Scudiero, S. Ha, J.L. Haan, Electrochemical oxidation of polyalcohols in alkaline media on palladium catalysts promoted by the 
addition of copper, Electrochimica Acta, 218 (2016) 133-139.

24. O. Muneeb, J. Estrada, T. Tran, S. Hu, B. Khorasani, A. Fry-Petit, L. Scudiero, S. Ha, J.L. Haan, Improved Electrochemical Oxidation of Polyalcohols in Alkaline Media on Palladium-Nickel Catalysts, ChemistrySelect, 2 (2017) 9261-9266.

25. H. Gao, J.-B. He, Y. Wang, N. Deng, Advantageous combination of solid carbon paste and a conducting polymer film as a support of platinum electrocatalyst for methanol fuel cell, Journal of Power Sources, 205 (2012) 164-172.

26. S. Mikhailov, Physics and applications of graphene: Experiments, BoD-Books on Demand, 2011.

27. V. Guzsvány, O. Vajdle, M. Gurdeljević, Z. Kónya, Ag or Au Nanoparticles Decorated Multiwalled Carbon Nanotubes Coated Carbon Paste Electrodes for Amperometric Determination of H 202 , Topics in Catalysis, 61 (2018) 1350-1361.

28. C. Xie, P.K. Upputuri, X. Zhen, M. Pramanik, K. Pu, Self-quenched semiconducting polymer nanoparticles for amplified in vivo photoacoustic imaging, Biomaterials, 119 (2017) 1-8.

29. M. Bedolla-Pantoja, Investigation of silver catalyst for propylene epoxidation: promotion and reaction mechanism, in, University of Delaware, 2010.

30. S. Pal, M. Sahoo, V.T. Veettil, K.K. Tadi, A. Ghosh, P. Satyam, R.K. Biroju, P.M. Ajayan, S.K. Nayak, T.N. Narayanan, Covalently connected carbon nanotubes as electrocatalysts for hydrogen evolution reaction through band engineering, ACS Catalysis, 7 (2017) 2676-2684.

31. A. Ali, D. Akyüz, M.A. Asghar, A. Koca, B. Keskin, Free-standing carbon nanotubes as non-metal electrocatalyst for oxygen evolution reaction in water splitting, International Journal of Hydrogen Energy, 43 (2018) 1123-1128.

32. X. Geng, J. Jing, Y. Cen, R. Datta, J. Liang, In situ synthesis and characterization of polyethyleneimine-modified carbon nanotubes supported PtRu electrocatalyst for methanol oxidation, Journal of Nanomaterials, 2015 (2015).

33. J. Ouyang, Applications of carbon nanotubes and graphene for third-generation solar cells and fuel cells, Nano Materials Science, 1 (2019) 77-90.

34. N. Barakat, M. Alajami, Z.K. Ghouri, S. Al-Meer, CoNi nanoparticles/CNT composite as effective anode for direct urea fuel cells, (2018).

35. B.M. Daas, S. Ghosh, Fuel cell applications of chemically synthesized zeolite modified electrode (ZME) as catalyst for alcohol electro-oxidation-a review, Journal of Electroanalytical Chemistry, 783 (2016) 308-315.

36. R. Vinodh, P.J.S. Rana, C.V. Muralee Gopi, Z. Yang, R. Atchudan, K. Venkatachalam, H.J. Kim, Polyaniline-13X zeolite composite-supported platinum electrocatalysts for direct methanol fuel cell applications, Polymer International, 68 (2019) 929-935.

37. J. Yao, Y. Yao, H. Mirzaii, Proton modified Pt zeolite fuel cell electrocatalysts, in: Renewable Energy in the Service of Mankind Vol I, Springer, 2015, pp. 173-182. 
38. I. Makertihartha, M. Zunita, Z. Rizki, P. Dharmawijaya, Recent advances on zeolite modification for direct alcohol fuel cells (DAFCs), in: AIP Conference Proceedings, AIP Publishing LLC, 2017, pp. 020030.

39. A. Fekry, The influence of chloride and sulphate ions on the corrosion behavior of Ti and Ti-6Al-4V alloy in oxalic acid, Electrochimica Acta, 54 (2009) 3480-3489.

40. A. Francis, S. Abdel-Gawad, M. Shoeib, Toward CNT-reinforced chitosan-based ceramic composite coatings on biodegradable magnesium for surgical implants, Journal of Coatings Technology and Research, (2021) 1-18.

41. D.D. Macdonald, Reflections on the history of electrochemical impedance spectroscopy, Electrochimica Acta, 51 (2006) 1376-1388.

42. A. Fekry, Impedance and hydrogen evolution studies on magnesium alloy in oxalic acid solution containing different anions, international journal of hydrogen energy, 35 (2010) 12945-12951.

43. S.A. Gawad, A. Nasr, A.M. Fekry, L.O. Filippov, Electrochemical and hydrogen evolution behaviour of a novel nano-cobalt/nano-chitosan composite coating on a surgical $316 \mathrm{~L}$ stainless steel alloy as an implant, International Journal of Hydrogen Energy, 46 (2021) 18233-18241.

44. W. Zhou, Y. Du, H. Zhang, J. Xu, P. Yang, High efficient electrocatalytic oxidation of formic acid on Pt/polyindoles composite catalysts, Electrochimica acta, 55 (2010) 2911-2917.

45. Y. Zhao, X. Yang, J. Tian, F. Wang, L. Zhan, Methanol electro-oxidation on Ni@ Pd core-shell nanoparticles supported on multi-walled carbon nanotubes in alkaline media, International journal of hydrogen energy, 35 (2010) 3249-3257.

46. R. Tammam, A. Fekry, M. Saleh, Electrocatalytic oxidation of methanol on ordered binary catalyst of manganese and nickel oxide nanoparticles, international journal of hydrogen energy, 40 (2015) 275283.

47. R.H. Tammam, A.M. Fekry, M.M. Saleh, Enhanced oxygen evolution reaction over glassy carbon electrode modified with $\mathrm{NiOx}$ and $\mathrm{Fe}_{3} \mathrm{O}_{4}$, Korean Journal of Chemical Engineering, 36 (2019) 19321939.

\section{Figures}



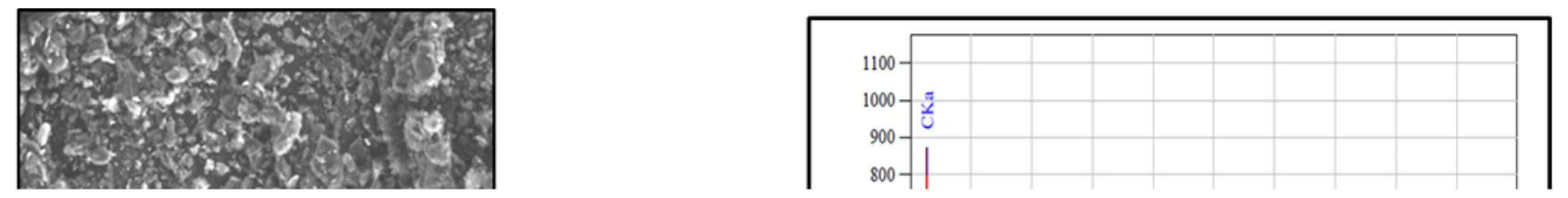

\section{Figure 1}

A SEM images for SMWZCPE modified electrode with different magnifications.

B EDX analysis for SMWZCPE modified electrode.

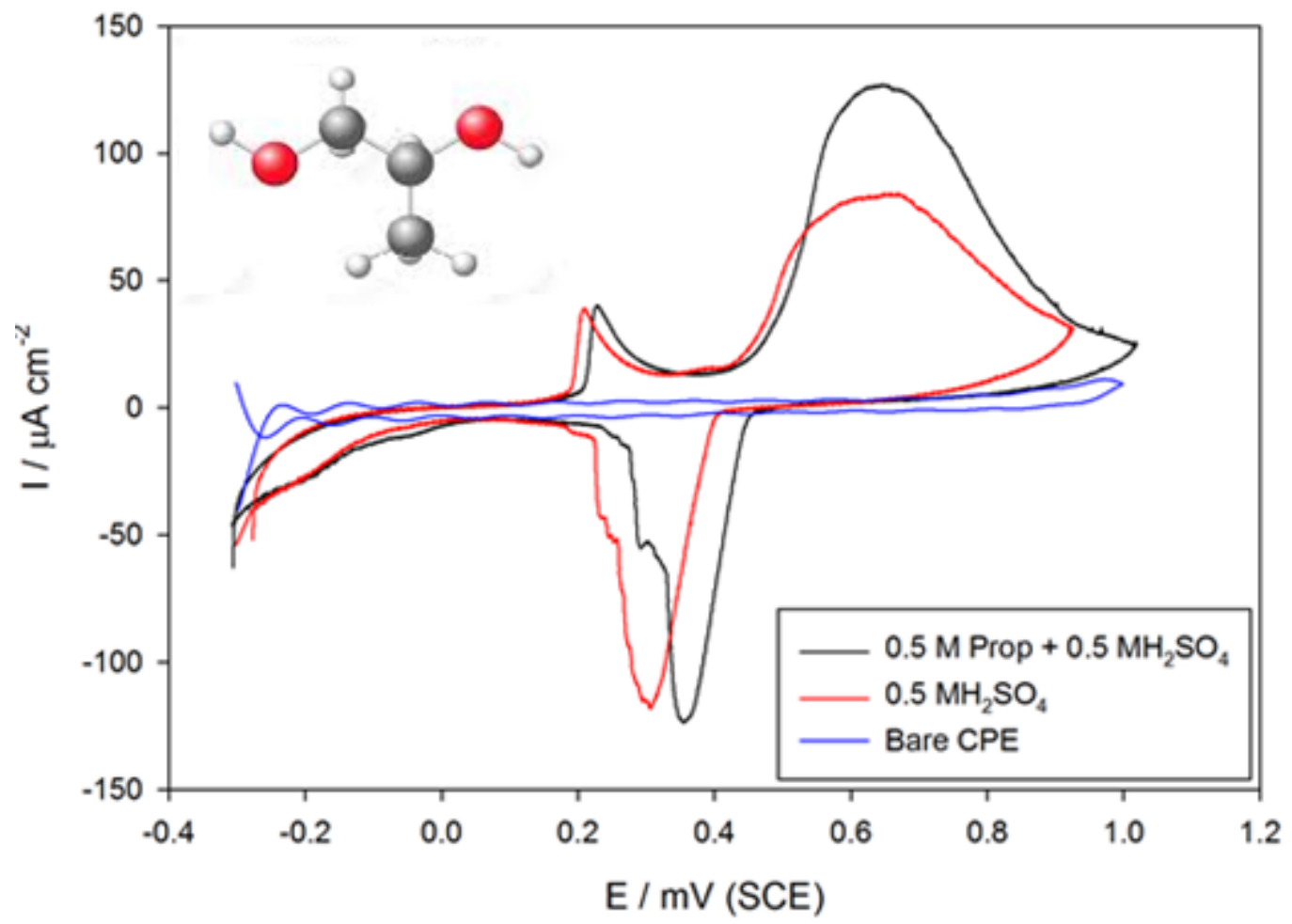

Figure 2 
CVs of bare CPE in $0.5 \mathrm{M} \mathrm{H}_{2} \mathrm{SO}_{4}$ and SMWZCPE in $0.5 \mathrm{M} \mathrm{H}_{2} \mathrm{SO}_{4}$ with and without $0.5 \mathrm{M}$ propylene glycol at scan rate of $100 \mathrm{mVs}^{-1}$

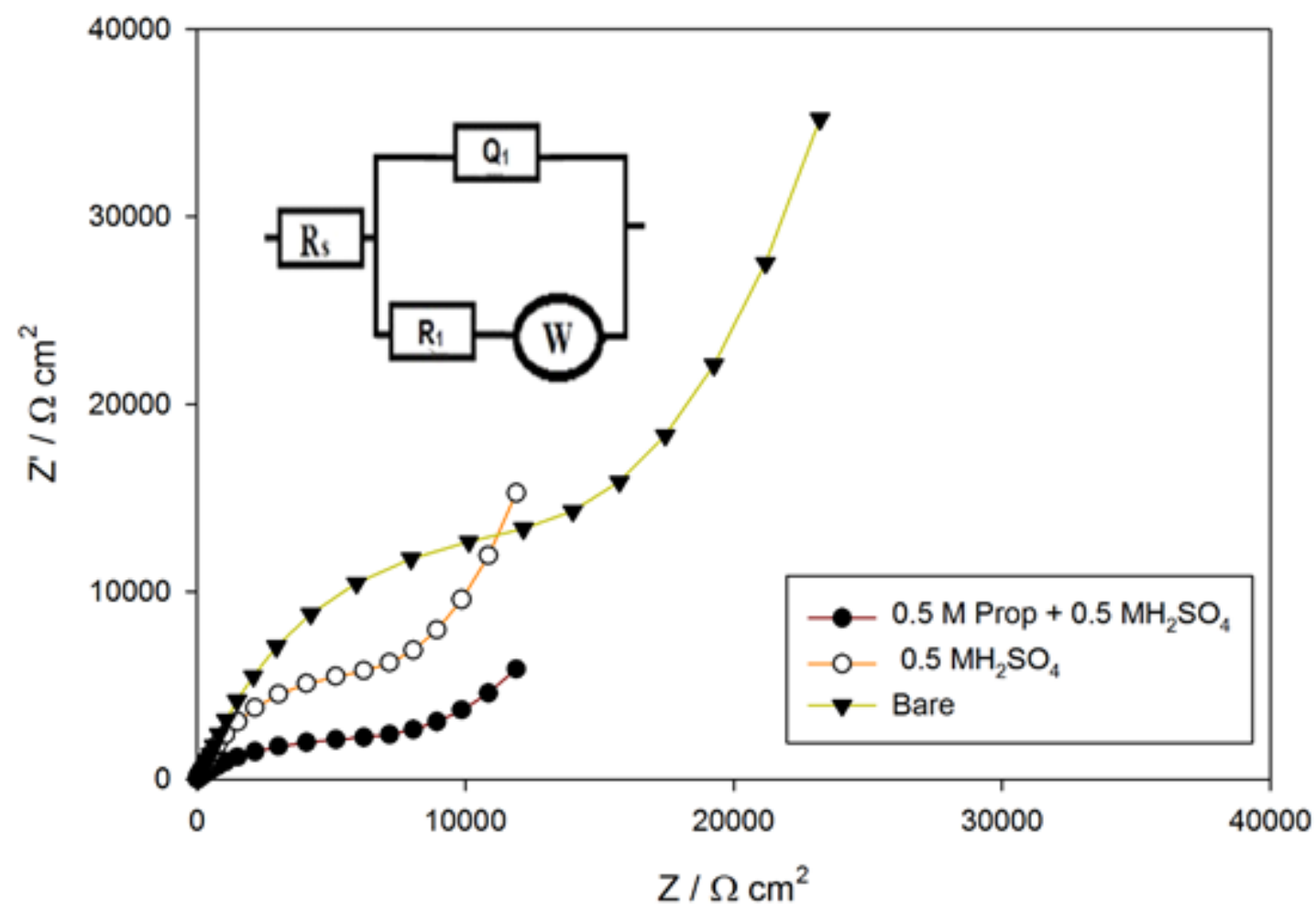

Figure 3

Nyquist plots of bare CPE in $0.5 \mathrm{M} \mathrm{H}_{2} \mathrm{SO}_{4}$ and SMWZCPE in $0.5 \mathrm{M} \mathrm{H}_{2} \mathrm{SO}_{4}$ with and without $0.5 \mathrm{M}$ propylene glycol

Inset: Fitting model (simple Randles model). 


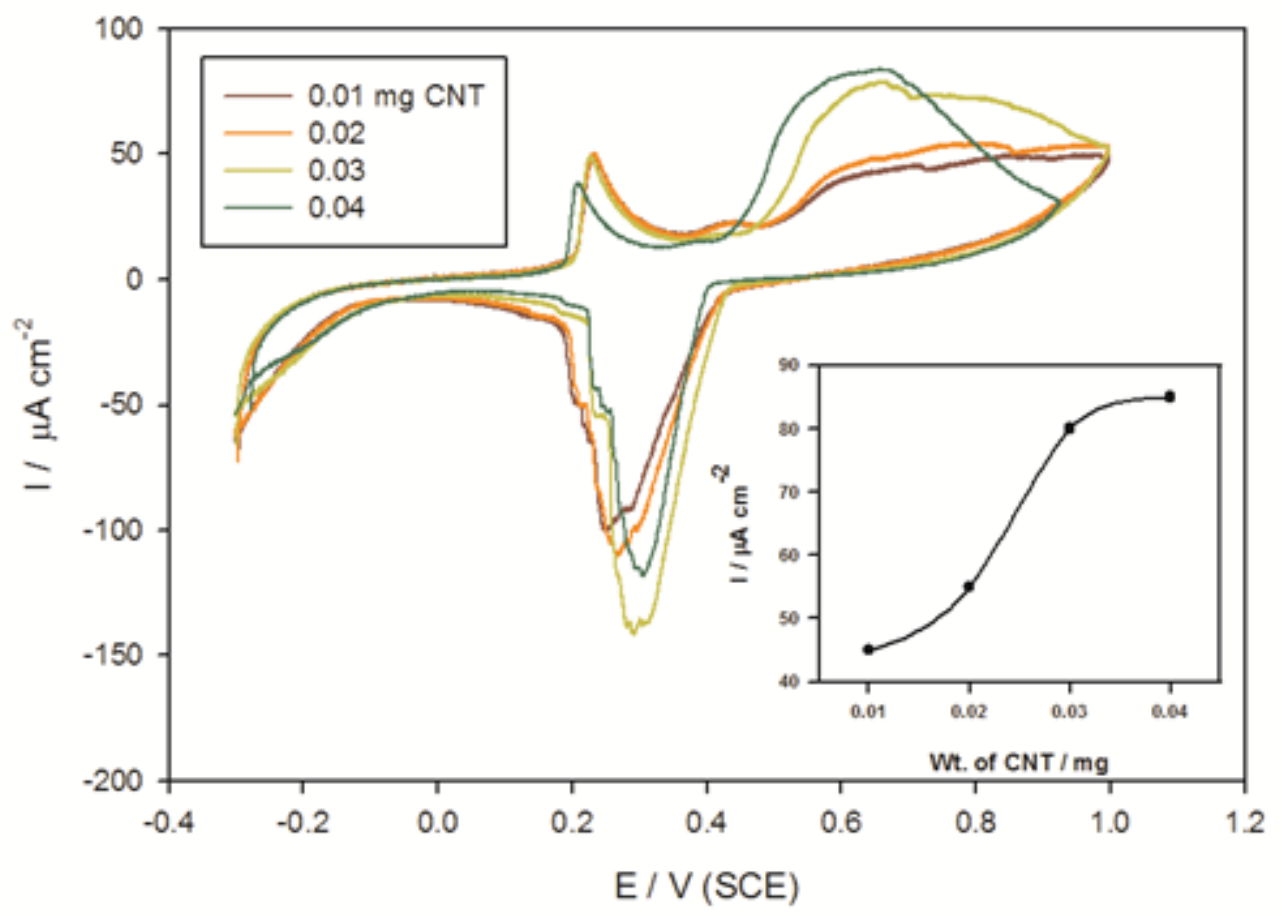

Figure 4

CVs of modified electrode SMWZCPE with various loading of CNT $(0.01-0.04 \mathrm{mg})$ in $0.5 \mathrm{M} \mathrm{H}_{2} \mathrm{SO}_{4}$ at scan rate of $100 \mathrm{mVs}^{-1}$

Figure 5

Effect of varying the scan rate from $\left(10-400 \mathrm{mVs}^{-1}\right)$ on the anodic peak current of SMWZCPE in $0.5 \mathrm{M}$ $\mathrm{H}_{2} \mathrm{SO}_{4}$

Figure 6

Effect of varying the scan rate from (10-500) $\mathrm{mVs}^{-1}$ on the anodic peak current of SMWZCPE in $0.5 \mathrm{M}$ $\mathrm{H}_{2} \mathrm{SO}_{4}$ with $0.5 \mathrm{M}$ propylene glycol 
Inset: the plot of the anodic peak current and the square root of scan rate

\section{Figure 7}

Effect of varying the propylene glycol concentration from $(0.01-0.5 \mathrm{M})$ on the anodic peak current of SMWZCPE in $0.5 \mathrm{M} \mathrm{H}_{2} \mathrm{SO}_{4}$

Inset: the plot of the anodic peak current and the propylene glycol concentration

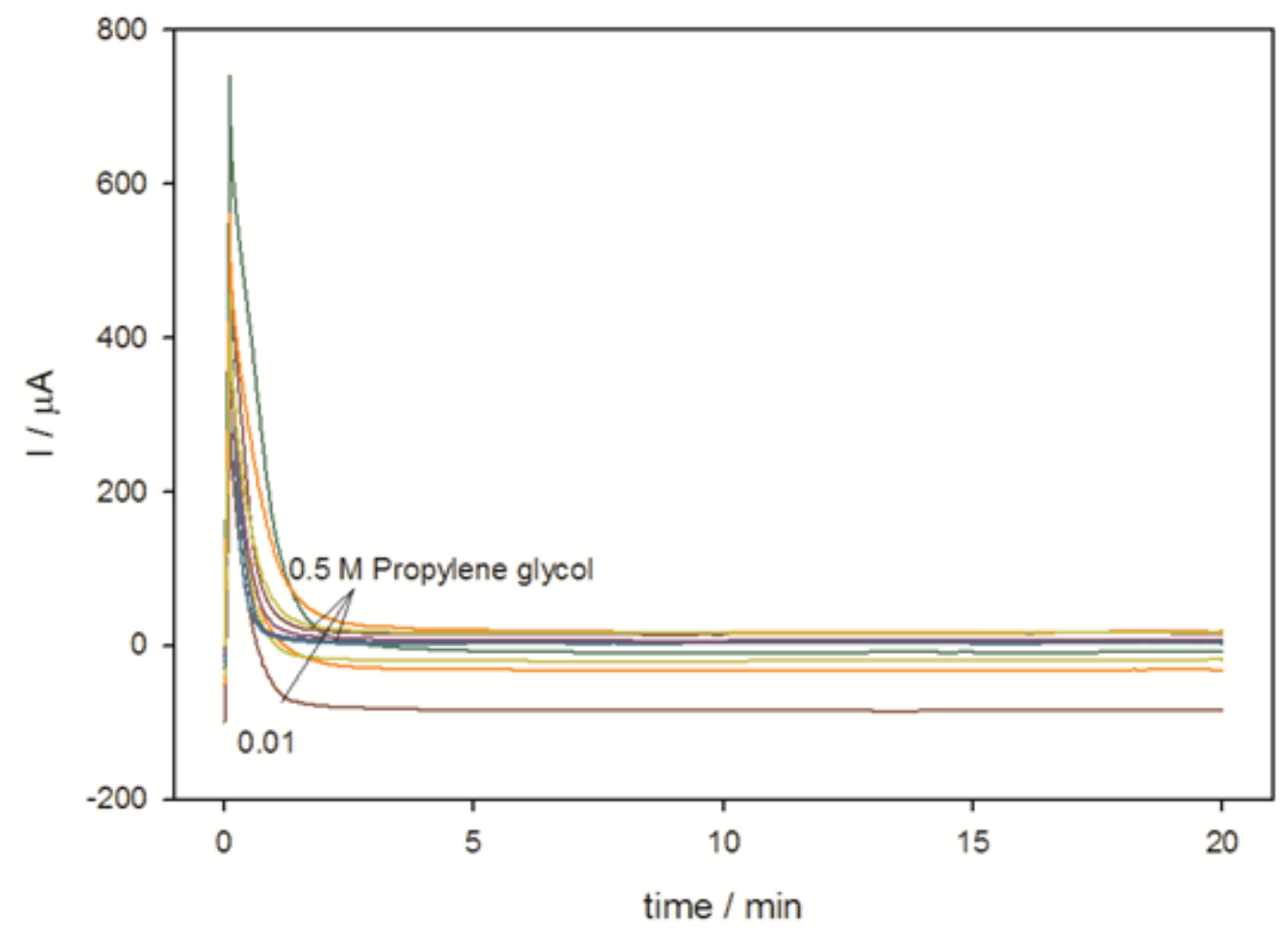

Figure 8

Chronoamperograms obtained at modified electrode SMWZCPE in $0.5 \mathrm{M} \mathrm{H}_{2} \mathrm{SO}_{4}$ using changed concentrations from $(0.01-0.5 \mathrm{M})$ propylene glycol. 